\title{
Somatic Mutations and Cancer
}

\author{
Muhammad Saleem ${ }^{1}$, Munir Ahmed ${ }^{2}$, Aamir Ali Abro ${ }^{3}$ and Gang \\ Chen $^{1 *}$ \\ ${ }^{1}$ College of Bioscience and Biotechnology, Yangzhou University, Jiangsu, China \\ ${ }^{2}$ College of Food Science and Engineering, Yangzhou University, Jiangsu, China \\ ${ }^{3}$ State Key Laboratory of Cotton, Biology Institute of Cotton Research Institute, Chi- \\ nese Academy of Agriculture Sciences Anyang (CAAS), PR China \\ *Corresponding Author: Gang Chen, College of Bioscience and Biotechnology, \\ Yangzhou University, Jiangsu, China.
}

Received: July 12, 2021

Published: August 19, 2021

(C) All rights are reserved by Gang Chen., et al.

\begin{abstract}
Most of the mutations that accumulate in somatic cells throughout the life time of a person do not have any effects but some mutations can cause serious consequences like cancer (which after originating from a single cell due to mutations in the genome starts to behave abnormally). There was a limited information of mutational processes and its consequences but recent advances in genome sequencing technologies due to unprecedented efforts has greatly revolutionized our understandings in this regard. In this review, I have briefly summarized about our current knowledge of the somatic mutations that that lead to cancer, its causes, possible ways which we are using for further studies and future premises.
\end{abstract}

Keywords: Somatic Mutations; Cancer; Aging; Genome; Repair Mechanism; Driver Mutations; Passenger Mutations; DNA Sequencing Technology

\section{Introduction}

Just like nothing has contributed to the flourishing of physics more than war, nothing has stimulated the development of biology more than cancer [1]. Cancer is responsible for one in eight deaths worldwide [2]. Genome determines the structure and functions of all organisms. At the time of identification of DNA as the carrier of genetic information, it was assumed to be a very stable molecule [3]. Genomes are very stable to continuously provide functions over the life time. Yet, they are far from immutable [4]. Later, it became clear that DNA is highly vulnerable to damage under physiological conditions. DNA mutations are changes in the genetic code and these mutations vary from the large chromosomal aberrations to smaller deletions, insertions and base substitutions. This tendency of DNA to undergo mutations is called as genome instability [4]. Free radicals generated due to cellular stressors, environmental stressors, and errors that occur during cellular replication increases the risk of mutations [5] by causing damage to DNA. Normally mutations are repaired by DNA repair systems but if the stressors cause mutations within the DNA mismatch repair or replication systems, then this can cause irreversible damage and loss of original genome template [4]. Loss in function of a gene can take place because mutations can build up faster than repair mechanism [6]. Exposure to UV radiations and certain chemicals compounds are also major causes of mutation. These mutations can cause serious outcomes in the form of diseases.

Rate of somatic mutations differ among different genome sequences. At areas like micro-satelites, mini-satelites, retrotransposons and telomeres, mutation rate is much higher because of the presence of repeat elements [4]. According to Sturtevant [7] genetic material is mutable at the rate subject to natural selection and too high or too low rate of mutations can lead to the extinction of a specie. DNA mutations are considered 


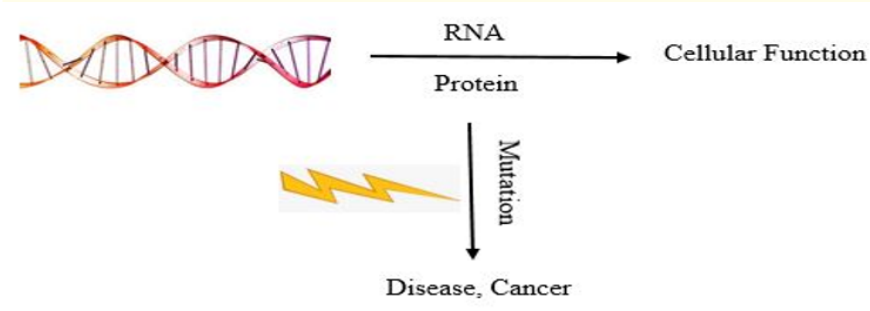

Figure 1: The genome contains all the information for the functions of the somatic cells but alterations in genome due to different mutagens can cause loss of instructions for the functions. These alteration in the genome can lead to serious consequences in the form of diseases like aging and cancer.

as hallmark for diseases like cancer [8], and aging [9]. The best documented consequence of somatic mutations is cancer [10]. The Cancer Census contains 572 genes [11] out of which approximately $90 \%$ are altered by somatic mutations. Ernest E Tyzzer [12] firstly used the term 'somatic mutation' with respect to a tumor. In 1919, Whitman [13] and David Hansemann [14] expanded the view of somatic mutations in cancer. According to David Hansemann, anaplasia was a hallmark of cancer and according to Whitmann, tumor cells were displaying anaplasia as mutated cells. But it became an irrefutable evidence only in1970s that cancer was a genetic disease caused by cycles of mutations [15]. According to Boveri, failure of cell division triggered cancer [16]. Recent studies tell us that all the cancers are caused by somatic mutations [17] that accumulate over the life time of a cancer patient [4]. Somatic mutations found in cancer genomes [18] are because of intrinsic slight infidelity of DNA replication machinery, exogenous or endogenous mutagen exposures, enzymatic modification of DNA or defective DNA repair. Because all the cancers arise due to somatically acquired changes in the DNA of cancer cell, that does not mean that all of these mutations are involved in the development of cancer. Due to recent studies it is highly expected that some mutations do not contribute at all [5].

Out of thousands of mutations only a handful of mutations have been positively selected [18]. To clearly express this concept, we use the terms 'driver' and 'passenger' mutations. Most of the somatic mutations are 'passengers' and these mutations do not take part later in causing diseases and these mutations often occur during cell division without any functional consequences. However, there are strong evidences that 'driver' mutations contribute to the development of cancer [5] and these are the mutations that conferred growth advantage. Studies have shown that there are several factors that are associated with increased risk of somatic mutations that cause cancer. Exposure to mutagens such as tobacco smoke can highly increase the risk of cancer. In lung cancer, the smokers on average are 10 -fold more at risk of somatic mutations in their cancer genomes as compared to non-smokers [19]. Age is another factor to consider because despite the presence of cancer in young people, the incidence and mortality of cancers increases exponentially with age [20]. Cellular aging leads to increase in mutational frequency and increased risk of carcinogenesis as genes responsible for replication begins to loss frequency [6]. It is an interesting feature that the somatic alterations are not frequently observed under the age of 50 . However after the age of 50 , detectable somatic alterations increase frequency. According to a recent study, frequency of mosaicism (state of being composed of cells of two genetically different types) increases exponentially with age [21]. Age-related increase in cancer risk is the universally accepted model of cancer. Now it is clear that somatic mutations in tumors id significantly higher in old patient as compared to young one [22]. The development of DNA sequencing by Sanger [23] allowed rapid examination of the genetic material contained by cancer cells. The rate at which somatic mutations occur in cancerous tissues are studies via sequencing and used to identify patterns in a tumor's growth state [24]. Multiple independent studies used Sanger sequencing of some exons of a cancer gene to provide clues to the aetiology of both endogenous and exogenous factors of human carcinogenesis.

The central goal of cancer genome analysis is the identification of cancer genes that carry driver mutations. However differentiation of drivers from passenger mutations is is the key challenge. The clustering of driver mutations in the subset of genes that are cancer genes is the clue which is used for the identification whereas, passenger mutation are randomly distributed. TP53 was usually selected for this analysis due to its higher prevalence of somatic mutations in almost all tumor classes [25]. The first release of the IARC TP53 database contained approximately 3,000 somatic mutations [26]. While the most recent (R16) version released in 2012 contains almost 30,000 somatic mutations in TP53 [27]. Recent advances in genotyping and sequencing technologies have enabled the resolution for characterizing genetic mosaicism which were previously not well characterized allowing for detection of somatic events in a small fraction of cells and even down to the single cell level. The examination of cancer exons (even whole 
cancer) genome is possible due to the development of next generation sequencing. A lot of work has been done without any doubt but still these studies are limited if we consider current population based studies in their ability to detect small mutated clones that effect small proportions of cells. These studies have limits of detection ranging from $5 \%$ to $15 \%$ of cells affected which are like the observing the tip of an iceberg [28]. Next generation sequencing studies are revealing patterns of somatic substitutions in different cancer types. The next generation sequencing is providing a deep look into the patterns of DNA changes across cancer genomes while resolving some of the previous limitations from TP53 studies.

\section{Conclusion and Future Prospective}

Though somatic mutations (in a moderate amount) are necessary because of their role in the adaptation of an organism in the environment but because it occurs randomly, it has more adverse effects in the form of diseases like cancer. For long, our knowledge of somatic mutations and its role in causing cancer was limited and unclear but recently made unprecedented efforts have greatly enriched our understandings in combating this issue. Despite of all these efforts, still much work is needed to done in this regard because of various unclear concepts still waiting to be resolved. Some of the unclear issues are:

- The study of established cancers has provided many clues about the temporal evolution of cancers, but many gaps in our understanding remain. It seems that a clone must acquire a handful of driver mutations to transform into a cancer. Despite of many years of systematic sequencing of thousands of cancer genomes, we have not yet determined the number of driver mutations required to make a tumor.

- $\quad$ Over millions of years, species have evolved protective mechanisms to keep the incidence of cancer low. These include highfidelity replication, DNA repair pathways, cellular senescence, stem cell hierarchies, tumor suppressor genes, immune surveillance, and micro environmental control of cellular behavior. Given the availability of protective mechanisms against cancer, why does cancer still exist?

- Together with the roughly geometric rise in cancer incidence predicted by the stepwise model of cancer, these evolutionary considerations can help to explain why cancer incidence is low, but not zero, in the young, as well as why incidence rises rapidly later in life.

\section{Bibliography}

1. Lichtenstein AV. "Genetic mosaicism and cancer: cause and effect”. Cancer Research 78.6 (2018): 1375-1378.

2. Goldblatt EM and WH Lee. "From bench to bedside: the growing use of translational research in cancer medicine". American Journal of Translational Research 2.1 (2010): 1.

3. Watson JD. "Molecular biology of the gene". Pearson Education India (2004).

4. Vijg J. "Somatic mutations, genome mosaicism, cancer and aging". Current Opinion in Genetics and Development 26 (2014): 141-149.

5. Greenman C., et al. "Patterns of somatic mutation in human cancer genomes”. Nature 446.7132 (2007): 153-158.

6. Simpson AG. "The natural somatic mutation frequency and human carcinogenesis". Advances in Cancer Research 71 (1997): 209-240.

7. Sturtevant A. "Essays on evolution. I. On the effects of selection on mutation rate". The Quarterly Review of Biology 12.4 (1937): 464-467.

8. Negrini S., et al. "Genomic instability—an evolving hallmark of cancer". Nature Reviews Molecular Cell Biology 11.3 (2010): 220-228

9. López-Otín C., et al. "The hallmarks of aging”. Cell 153.6 (2013): 1194-1217.

10. Tate JG., et al. "COSMIC: the catalogue of somatic mutations in cancer". Nucleic Acids Research 47 (2019): D941-D947.

11. Martincorena I., et al. "Somatic mutant clones colonize the human esophagus with age". Science 362.6417 (2018): 911-917.

12. Wunderlich V. "Early references to the mutational origin of cancer". International Journal of Epidemiology 36.1 (2007): 246-247.

13. Whitman R. "Somatic Mutations as a Factor in the Production of Cancer: A Critical Review of v. Hansemann's Theory of Anaplasia in the Light of Modern Knowledge of Genetics". The Journal of Cancer Research 4.2 (1919): 181-202.

14. Hansemann D. "Ueber asymmetrische Zelltheilung in Epithelkrebsen und deren biologische Bedeutung". Archiv für pathologische Anatomie und Physiologie und für klinische Medicin 119.2 (1890): 299-326. 
15. Nowell PC. "The clonal evolution of tumor cell populations". Science 194.4260 (1976): 23-28.

16. Hoenicke $\mathrm{L}$ and L Zender. "Immune surveillance of senescent cells-biological significance in cancer-and non-cancer pathologies". Carcinogenesis 33.6 (2012): 1123-1126.

17. Alexandrov LB., et al. "Mutational signatures associated with tobacco smoking in human cancer". Science 354.6312 (2016): 618-622.

18. Michael RS., et al. "The cancer genome". Nature 458.7239 (2009): 719-724.

19. Imielinski M., et al. "Mapping the hallmarks of lung adenocarcinoma with massively parallel sequencing". Cell 150.6 (2012): 1107-1120.

20. Yancik R and LA Ries. "Cancer in older persons: an international issue in an aging world". in Seminars in oncology. Elsevier (2004).

21. Loftfield E., et al. "Predictors of mosaic chromosome Y loss and associations with mortality in the UK Biobank". Scientific Reports 8.1 (2018): 1-10.

22. Welch JS., et al. "The origin and evolution of mutations in acute myeloid leukemia”. Cell 150.2 (2012): 264-278.

23. Bina-Stein M., et al. "Rapid sequence determination of late simian virus $4016 \mathrm{~S}$ mRNA leader by using inhibitors of reverse transcriptase". Proceedings of the National Academy of Sciences 76.2 (1979): 731-735.

24. Taniguchi H. "Badanie wpływu wybranych mutacji genu BRAF na rozwój nowotworu wątroby-badania modelowe z wykorzystaniem linii komórkowych ssaków".

25. Greenblatt M. "Mutations in the p53 tumor suppressor gene: clues to cancer etiology and molecular pathogenesis". Cancer Research 54 (1994): 4855-4878.

26. Cariello NF., et al. "Database and software for the analysis of mutations in the human p53 gene". Cancer Research 54.16 (1994): 4454-4460.

27. Alexandrov LB and MR Stratton. "Mutational signatures: the patterns of somatic mutations hidden in cancer genomes". Current Opinion in Genetics and Development 24 (2014): 52-60.

28. Machiela MJ and SJ Chanock. "Detectable clonal mosaicism in the human genome". in Seminars in hematology. Elsevier (2013).
Volume 3 Issue 9 September 2021 (C) All rights are reserved by Gang Chen., et al. 